\title{
O ENSINO DE ÁCIDOS E BASES A PARTIR DO INDICADOR NATURAL PRODUZIDO COM AÇAÍ (Euterpe oleracea Mart) ${ }^{1}$
}

\author{
Rafaela de Jesus Silva \\ Josimara Cristina de Carvalho-Oliveira ${ }^{3}$ \\ Iracilma da Silva Sampaio ${ }^{4}$ \\ Cassia Patrícia Muniz de Almeida 5 \\ André Camargo de Oliveira ${ }^{6}$
}

\begin{abstract}
Resumo
O presente trabalho retrata uma atividade diferenciada realizada com alunos do $3^{\circ}$ ano do Ensino Médio no Ensino de Química, de uma escola pública de Rorainópolis-Roraima. Durante o estágio supervisionado IV, observou-se a dificuldade dos educandos em assimilar a temática retratada nas aulas, pois, somente exposições teóricas não lhes despertavam o interesse. Por isso, essa pesquisa apresenta o ensino de ácidos e bases utilizando um indicador alternativo a partir do açá, visando melhorar o entendimento dos estudantes, através de uma ação contextualizada. O extrato do açaí atua como solução indicadora de substâncias ácidas e alcalinas, uma vez que, seus pigmentos naturais são responsáveis pelas alterações na coloração de acordo com o meio. Os resultados demonstraram que o fruto é uma boa opção para se usar como indicador, pois, realiza tal função de forma muito satisfatória, através da variação de cor. Trata-se de uma metodologia simples e de baixo custo, sendo uma boa escolha em escolas sem laboratórios ou materiais adequados. A proposta auxiliou os estudantes a compreender a importância das aplicações do assunto discutido no cotidiano e como seus conhecimentos são essenciais na atualidade. A dinâmica propiciou a abordagem e discussão de conteúdos de Química, bem como sua analogia com aspectos da vida diária dos alunos.
\end{abstract}

Palavras-chave: Ensino de Química. Materiais Alternativos. PIBID.

\section{INTRODUÇÃO}

Os estudantes geralmente encaram os conteúdos de Química como sendo de complexa apreensão, é de grande responsabilidade do professor e da instituição de ensino despertar nos alunos a curiosidade e o interesse pela disciplina. Entretanto, a realidade das escolas do município de Rorainópolis envolve uma série de dificuldades como: a carência de laboratório,

\footnotetext{
${ }^{1}$ Projeto com apoio Financeiro do Programa Institucional de Bolsas de Iniciação à Docência (Pibid).

${ }^{2}$ Acadêmica do curso de Ciências da Natureza com ênfase em Ciências Biológicas e Química da Universidade Estadual de Roraima, UERR Campus Rorainópolis. E-mail: rafaela.de.jesus.silva@ hotmail.com.

${ }^{3}$ Doutora em Química. Professora da Universidade Estadual de Roraima - UERR Campus Rorainópolis. E-mail: josi903@yahoo.com.br;

${ }^{4}$ Mestre em Ensino de Ciências. Professora da E. E. José de Alencar. E-mail: iracilmasampaio@ hotmail.com;

${ }^{5}$ Mestranda em Ensino de Ciências. Professora da E. E. José de Alencar, Rorainópolis-RR. E-mail: cassia.patricia@hotmail.com.

${ }^{6}$ Doutor em Química. Professor da Universidade Estadual de Roraima - UERR Campus Rorainópolis. Coordenador do PIBID.E-mail: acco9995@yahoo.com.br
} 
equipamentos, vidrarias e reagentes. Assim, é preciso buscar alternativas que contornem essa problemática e auxiliem no processo de ensino e aprendizagem dos alunos.

Uma oportunidade promissora para o ensino da Química seria a ampliação dos conceitos a partir da análise e participação dos educandos em aulas experimentais, propiciando que eles compreendam as alterações químicas que ocorrem no mundo físico de modo abrangente e coligado (DIAS, GUIMARÃES e MERÇON, 2003).

A contextualização é um recurso que oferece sentido à ciência expandindo as probabilidades de influência mútua e colabora expressivamente para diminuir a divisão entre teoria e prática.

O ensino apenas tradicional, com resolução de exercícios recomendados pelos professores, impede que os estudantes aproveitem os conhecimentos obtidos em sala de aula somente e, também, de arrolá-los com o que acontece ao seu redor (DIAS, GUIMARÃES e MERÇON, 2003). No ensino de Química as atividades experimentais proporcionam ao aluno uma concepção de como esse conhecimento se forma e se desenvolve, observando a reação no momento em que ocorre.

A utilização de experimentos é de grande relevância, e a disciplina de Química é uma ciência experimental, de constatação científica, proferida a suposições teóricas, e de tal modo o conceito da concretização de experimentos é defendida como ampla tática didática para o ensino e aprendizagem dos estudantes. Conforme os Parâmetros Curriculares Nacionais PCN's para o Ensino Médio, a metodologia de experimentação pode ser entendida como um direito do educando, pois, origina debates sobre tópicos que se tornam aparentes (PENAFORTE e SANTOS, 2014).

É importante proporcionar ao aluno eventos com mais significado, notáveis e mensuráveis, uma vez que as opiniões que o aluno apresenta para a sala de aula sobrevêm principalmente de sua leitura do mundo. Uma ocasião ideal para se desempenhar uma aula distinta é o ensino de ácidos e bases, e como verificar sua ocorrência, porque, essas substâncias são essenciais para a manutenção da vida e têm uma variedade enorme de aplicações no cotidiano.

Um exemplo é o ácido clorídrico $(\mathrm{HCl})$ que está presente no estômago, participando na digestão dos alimentos. Outros ácidos se encontram no vinagre e nas frutas azedas como: o limão, a laranja, o maracujá, entre outros. Já as bases podem ser exemplificadas por frutas verdes que possuem o sabor adstringente, como: a banana verde, muito apreciada em Roraima na forma de chips feito em casa. 
Para descobrir se uma substância é ácida ou básica podem ser utilizados indicadores ácido-base. Tais substâncias químicas ao serem adicionadas a uma solução aquosa são capazes de indicar se ela é ácida ou básica de acordo com seu potencial hidrogeniônico $(\mathrm{pH})$, o qual é a concentração de íons hidrogênio $\left(\mathrm{H}^{+}\right)$em uma determinada solução (CONSTANTINO, SILVA e DONATE, 2004).

Damasceno et al., (2005) expõe o açaí (Euterpe oleracea Mart) como indicador ácidobase. A cor roxa avermelhada característica do açaí deve-se às antocianinas, pigmentos naturais que são responsáveis pela coloração azul, vermelha e roxa de diversos tecidos vegetais, inclusive flores e frutos. Essas substâncias competem à classe dos flavonoides e são as responsáveis pela mudança na coloração de soluções em função do pH do meio em que estão dispostas. O estudo das antocianinas como indicador ácido-base vem sendo discutido na literatura (COSTA et al., 2015).

A utilização de materiais presentes no cotidiano comporta uma maior compreensão e apropriação do assunto proposto em sala de aula. A preferência pela matéria-prima, Euterpe oleracea, se deu, principalmente, por ser uma espécie nativa e de conhecimento de todos os alunos da região do sul do Estado de Roraima, local dessa pesquisa, promovendo o acesso aos materiais necessários e, possibilitando ainda mostrar aplicações alternativas para o açaí.

O emprego de um indicador ácido-base produzido através do açaí também chama a atenção dos estudantes por ser de baixo custo e de simples elaboração. Assim, o uso dos indicadores naturais é analisado como uma excelente opção quando se deseja trabalhar essa temática, realizando experimentos em sala de aula.

Com base no exposto, essa pesquisa tem como objetivo o ensino do conteúdo de ácidos e bases com o auxílio de um indicador alternativo de açaí. E para atingir o objetivo geral foram traçados os seguintes objetivos específicos: diagnosticar aquilo que os estudantes já tinham conhecimento sobre o assunto com a aplicação de um questionário diagnóstico; proporcionar o entendimento dos conceitos, por meio de uma prática contextualizada; avaliar os resultados da proposta através de um questionário final. A pesquisa foi aplicada em uma escola estadual, situada no município de Rorainópolis, localizado na região sul de Roraima, a $298 \mathrm{~km}$ da capital Boa Vista.

\section{O açaí como tema de ensino}

Qualquer ferramenta para o ensino de Química, como o uso de imagens, sons, simulações, experimentação, utilização do livro didático, jogos, etc, quando aplicados 
adequadamente, pode promover aos estudantes o acesso ao conhecimento em circunstâncias de ensino onde outros padrões foram apontados até então como impotentes (SOUZA, 2011).

Múltiplos recursos didáticos e materiais podem ser usados no ensino, inclusive ao mesmo tempo, com a finalidade de retirar de cada um as principais informações que viabilizem o aporte pedagógico. Contudo, devem-se priorizar aqueles que admitam ampla interatividade com a mínima necessidade de recursos financeiros. Sendo assim, o professor deve focar a atividade em objetivos específicos para facilitar a aprendizagem do educando e realiza-la com êxito. No caso de uma aula experimental, o aluno deve ser avisado de que um experimento pode servir para distintos objetivos (SOUZA, 2011).

Segundo Penaforte e Santos (2014) as atividades experimentais no ensino de Química permitem ao aluno uma concepção de como a química se edifica e se amplia, presenciando a reação no momento em que ela acontece. O aprendizado voltado para o cotidiano, por meio de exposições experimentais, com instrumentos de fácil alcance e uso corriqueiro, evidenciouse uma escolha capaz de instigar os estudantes para a aprendizagem de conteúdos de Química no ensino médio. Nesse trabalho, desenvolveram-se experiências fundamentadas nas cores de substâncias contidas no açaí, obtidas através da técnica de extração alcoólica.

$\mathrm{O}$ uso de corantes naturais retirados de algumas plantas apresentam potencial como indicadores de $\mathrm{pH}$ e podem ser utilizados como recurso didático alternativo nas técnicas experimentais em escolas de ensino médio. Através da acidez ou basicidade do elemento em que se dispõem esses corantes exibem várias cores, servindo como um instrumento para o processo de ensino/aprendizagem, nas aulas que abrangem reações ácido-base, ajudando na identificação de distintas soluções (LUCAS et al.,2013).

Conforme Terci e Rossi (2002) a utilização de indicadores de pH é uma técnica bem antiga introduzida por Robert Boyle, no século XVII. Boyle organizou um licor de violeta e notou que o extrato desta flor, em solução ácida, se tornava vermelha e em solução básica, verde. Assim, foram obtidos os primeiros indicadores de $\mathrm{pH}$ em ambas as formas: solução e papel. Em seguida, Boyle determinou que ácido fosse um conteúdo capaz de alterar a coloração de extratos vegetais. Apenas no princípio do século XX, Willstätter e Robinson descreveram as antocianinas como pigmentos responsáveis pela tonalidade de várias flores e que seus extratos exibiam cores que se modificavam em função da acidez ou basicidade do meio. Observou-se que as antocianinas apresentam coloração avermelhada em meio ácido, violeta em meio neutro e azul em espécies alcalinas, explicando assim as variações de cores de extratos de plantas ressaltadas por Boyle. 
Menezes-Costa et al., (2015) apresentou o açaí como fruto com alto teor de antocianinas, o que o caracteriza como excelente indicador ácido-base e perceberam que o uso de materiais do cotidiano permite uma maior compreensão e absorção do assunto que é desenvolvido em sala de aula, uma vez que chama atenção dos estudantes por ser de fácil elaboração e de custo acessível.

A Euterpeoleracea foi escolhida como matéria prima por ser uma espécie nativa e do conhecimento de todos os alunos da região, de fácil acesso aos materiais necessários e, além disso, pela possibilidade de revelar aplicações alternativas para o açaí e de transmitir o conhecimento de suas propriedades químicas.

\section{METODOLOGIA}

A pesquisa tem abordagem qualitativa, uma vez que se preocupa com aspectos da realidade que não podem ser quantificados, ponderando a explicação dos acontecimentos, a imputação de significados e as relações sociais (GERHARDT e SILVEIRA, 2009).

Quanto aos objetivos é uma pesquisa descritiva visando à definição das características de um determinado grupo e participante, pois, os pesquisadores e a amostra estiveram envolvidos ativamente no processo da pesquisa (GIL, 2008).

Quanto aos procedimentos técnicos, é uma pesquisa de campo que ocorreu dentro da sala de aula, e procurou elementos em torno das dificuldades presentes nas próprias fontes de investigação, com objetivos predefinidos (PRODANOV e FREITAS, 2013). O campo escolhido foi uma escola pública de Rorainópolis-RR, por ser o município onde a pesquisadora reside, estuda e desenvolve suas atividades como bolsista do PIBID.

Esse tipo de pesquisa tem validade, porque as variáveis não são influenciadas pelo pesquisador, tornando-se uma investigação mais aberta, onde os resultados obtidos foram registrados exatamente como ocorreram no ambiente de pesquisa, sendo analisados e interpretados com fundamentação teórica esclarecida (FLICK, 2009).

Aplicaram-se dois questionários, um para diagnosticar aquilo que os alunos já tinham conhecimento, e outro no final do projeto para identificar a eficácia da proposta. Ambos os questionários continham questões abertas e fechadas. O questionário com perguntas fechadas propicia retornos mais breves, ademais é uma ferramenta de coleta de dados que precisa ser aplicada sem a interferência do pesquisador para garantir sua veracidade. Os questionários com perguntas abertas propiciam a obtenção de elementos livres e opiniões do pesquisado, empregando elocução própria (RAMPAZZO, 2005). 
A população envolveu alunos do $3^{\circ}$ ano do ensino médio regular. A amostra contou com 35 educandos e um professor de química. Gerhardt e Silveira (2009), afirmam que a amostragem procura sugerir uma parcela da população, de maneira que expresse, na medida do possível, o todo. A pesquisa utilizou a amostragem por conveniência onde a pesquisadora selecionou o ambiente, admitindo que este possa representar um universo de estudos qualitativos (CARMO e FERREIRA, 2008).

O projeto contou com duas etapas, descritas a seguir:

$\mathrm{Na}$ primeira aula o projeto foi apresentado aos estudantes para que eles compartilhassem de sua importância e respondessem ao questionário diagnóstico, este buscou saber o que os alunos aprenderam sobre ácidos e bases. Considerando que este conteúdo foi visto no $1^{\circ}$ ano do ensino médio, o projeto permitiu a revisão para os estudantes que pretendiam prestar vestibular no final do ano letivo. Após recolher os questionários, deu-se início a explicação sobre a parte teórica de ácidos e bases e sua relevância no cotidiano (essa etapa ocorreu em 40 minutos), envolveu a utilização de recursos como quadro, pincel e questionamentos diversos.

Na segunda aula a pesquisadora abordou sobre a relevância dos indicadores naturais para o ensino de ácidos e bases dando ênfase ao açaí. Logo após, deu-se início a aula demonstrativa. Além do açaí mencionou-se a respeito de outros indicadores naturais que os alunos poderiam produzir em casa, como: indicador de repolho roxo.

No decorrer da aula prática o conteúdo foi sendo discutido com a participação ativa dos alunos, compreendendo as propriedades ácidas e básicas, inclusive de outros produtos presentes no cotidiano dos estudantes. Em seguida, aplicou-se o questionário final para verificar se a proposta auxiliou na aprendizagem do assunto ministrado e se as aulas foram gratificantes no sentido de promover a aquisição do conhecimento (essa etapa ocorreu em 60 minutos).

\section{Materiais e métodos utilizados}

Os procedimentos usados na extração do indicador de açaí se amparou em Santos et al.,(2012) em que afirmam que a via alcoólica de extração de pigmentos é a mais adequada. Preparou-se o extrato do açaí dissolvendo $50 \mathrm{~g}$ de sua polpa em $100 \mathrm{~mL}$ de álcool etílico comercial, filtrando-se a mistura a seguir e armazenando em um recipiente plástico onde ficou descansando por aproximadamente 24 horas. 
Em seguida, colocaram-se em alguns copos as substâncias a serem testadas, foram adicionadas algumas gotas da solução indicadora em cada um deles e observou-se a mudança de tonalidade. Foram utilizados materiais alternativos de baixo custo e de fácil acesso, listados na Tabela 1 com seus respectivos preços.

Tabela 1: Materiais utilizados no projeto.

\begin{tabular}{|l|r|}
\hline \multicolumn{1}{|c|}{ MATERIAIS } & PREÇO (R\$) \\
\hline Açaí (1 Kg) & 10,00 \\
\hline Água sanitária & 2,50 \\
\hline Álcool etílico comercial & 2,50 \\
\hline Bicarbonato de sódio & 3,00 \\
\hline Sabão em pó & 3,00 \\
\hline Limão & 0,25 \\
\hline Vinagre & 2,50 \\
\hline & TOTAL \\
\hline
\end{tabular}

\section{RESULTADOS E DISCUSSÃO}

\section{Análise do questionário diagnóstico}

Ao serem questionados se gostavam ou não do fruto, todos os estudantes afirmaram com entusiasmo que gostavam muito de açaí e que costumam consumir o fruto com frequência, nas mais variadas formas, seja apenas com açúcar, com farinha de mandioca ou de tapioca, com leite condensado, amendoim, granola, com banana, etc. Porém, apenas 17,2\% dos estudantes afirmaram conhecer alguns dos nutrientes presentes na Euterpe oleracea, tal dado mostra que apesar de gostarem bastante de açaí, a maioria dos estudantes nunca buscou conhecer seus benefícios para a saúde.

Quanto à relação do açaí com os estudos de ácidos e bases, apenas 2,9\% deles responderam que sabiam dessa possibilidade, pois, essa temática já havia sido apresentada para eles. Esse resultado demonstra a heterogeneidade da sala, onde a maioria dos estudantes não teve esse tipo de contextualização.

Verificando o conhecimento sobre a coloração do açaí, apenas 14,3\% disse que sabiam, porém utilizaram frases vagas como, por exemplo: “por que é da natureza, o próprio 
açaí já é dessa cor". Essa resposta mostrou o desconhecimento sobre o real motivo da coloração do fruto.

Para finalizar o diagnóstico foi apresentada a seguinte questão aos alunos: "você acredita que os experimentos podem ser boas ferramentas no processo de ensino/aprendizagem? Justifique." A resposta dos alunos a essa questão foi bastante interessante, pois, todos eles acreditam que os experimentos promovem o aprendizado e deram as seguintes justificativas:

Aluno 1 "melhora o aprendizado, pois facilita o entendimento";

Aluno 2 "por que com os experimentos fica melhor para aprender os processos que estão ocorrendo";

Aluno 3 "por que eu acredito que na prática é mais fácil para aprender."

Tais respostam indicam que os estudantes sentem a necessidade de observar na prática como ocorrem os processos químicos, que na maioria das vezes só são mostrados de forma teórica. A proposta da aula diferenciada surgiu a partir do momento em que foi detectada a dificuldade dos alunos em perceber a química no cotidiano em que estão inseridos, durante as ações do PIBID como suporte ao professor titular.

A utilização da polpa de açaí como indicador ácido-base, teve como objetivo levar os alunos à compreensão de que frutas com antocianinas podem ser utilizadas como indicadores naturais, pois, tais substâncias são responsáveis pelas variações na coloração de acordo com o meio em que se encontram (DAMASCENO et al., 2005). Para as substâncias testadas obtiveram-se as tonalidades que são apresentadas na (Figura 4).

Figura 4. Variação na coloração do indicador ácido-base natural de açaí. Da esquerda para a direita tem-se: bicarbonato de sódio; sabão em pó; água sanitária; limão; vinagre.

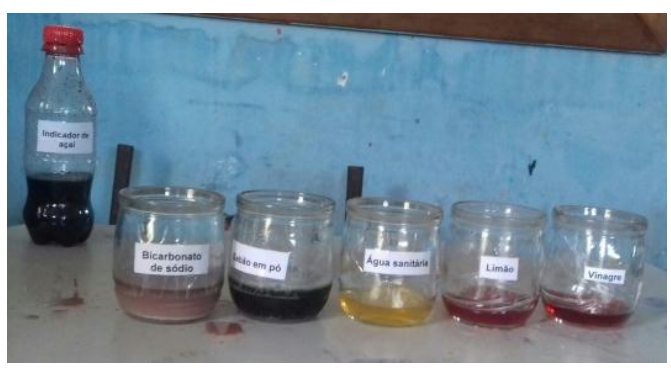

Fonte: os autores. 
Em meio ácido (limão e vinagre) o indicador preparado apresentou coloração vermelha e em meio básico as colorações lilás, esverdeada e amarela que é o caso do bicarbonato de sódio, do sabão em pó e da água sanitária respectivamente.

Em distintos pHs, os extratos assumem diferentes colorações que podem ser facilmente identificadas por observação visual, definindo-se escalas de $\mathrm{pH}$ em função da cor da solução resultante (TERCI e ROSSI, 2002).

Conforme Damasceno et al., (2005) as variações de cores notadas demonstram que o extrato de açaí pode ser utilizado como indicador de $\mathrm{pH}$, pois, torna-se vermelho em soluções ácidas $(\mathrm{pH}<7,0)$ e verde em soluções básicas $(\mathrm{pH}>7,0)$.

Os resultados de cores obtidos com os experimentos e a proposta descrita nesse artigo estão de acordo com Terci e Rossi (2002), Damasceno et al., (2005), Penaforte e Santos (2014), Menezes-Costa et al., (2015), dentre os demais autores citados e não foram encontrados artigos que contradigam o que foi exposto.

\section{Análise do questionário final}

Para verificar a eficácia da aula diferenciada foi aplicado um segundo questionário. $\mathrm{O}$ primeiro aspecto analisado foi se os estudantes gostaram de participar do experimento, e 100\%afirmaram que sim, dando algumas justificativas como:

Aluno 1: “os experimentos são interessantes, pois ajudam a entender melhor o assunto proposto e deixam a aula mais atraente";

Aluno 2: "por que é muito bom trazer experimentos para a sala de aula e assim conseguem chamar a atenção dos alunos e estes adquirem mais conhecimento".

Em seguida, foi questionado qual seria o motivo de o açaí funcionar como indicador ácido-base e 95,55\% dos estudantes soube responder tal questão, em que um dos comentários é transposto a seguir:

Aluno3: "por que o açaí contém antocianinas que mudam sua coloração conforme a acidez ou basicidade do meio em que se encontram".

$\mathrm{Na}$ sequência, os alunos analisaram se o conhecimento obtido com as aulas auxiliara na construção do seu conhecimento e 91,4\% dos alunos afirmaram que sim, conforme a justificativa do Aluno4: "aumenta a possibilidade de aprendizagem no decorrer do assunto por ser uma maneira mais agradável de se aprender e ainda estudamos sobre as substâncias contidas no açaí”. 
$\mathrm{Na}$ questão seguinte, buscou-se descobrir se as aulas práticas relacionadas com o cotidiano contribuem para despertar o interesse dos estudantes pela química e 95,55\%dos alunos afirmaram que as aulas diferenciadas cooperam no seu interesse pela disciplina e fizeram alguns comentários:

Aluno 1 "por que geralmente as aulas de química são meio complicadas para entender e as aulas práticas ajudam na compreensão";

Aluno 2 "por que a aula fica muito interessante e conseguimos compreender os assuntos e até quem não gosta de química acaba gostando".

Para finalizar o questionário, os educandos foram questionados quanto à capacidade de identificarem substâncias ácidas e básicas no cotidiano, e 95,55\% dos pesquisados deram como exemplos de ácidos o limão e o vinagre, refrigerantes de cola, café e produtos de limpeza, fermento e sal de fruta como substâncias básicas. Esse fato mostra que os estudantes entenderam os conceitos abordados, e conseguiram citar exemplos distintos daqueles que foram apresentados, assinalando assim a eficácia da proposta.

\section{CONSIDERAÇÕES FINAIS}

O aprendizado em torno do cotidiano, por meio de aulas experimentais com materiais de fácil obtenção e uso comum, evidenciou-se uma alternativa satisfatória para instigar os estudantes para o ensino de conteúdos de ácidos e bases.

A atividade propiciou a abordagem e discussão dos conteúdos, bem como sua analogia com aspectos da vida diária dos alunos. Dessa maneira, uma ampla participação dos estudantes foi alcançada, em decorrência de sua maior motivação e interesse.

O método adotado também pode possibilitar ao professora outra concepção de ensino, distinta da tradicional, proporcionando a formação de uma nova geração de educadores em Química, que se preocupam com um ensino/aprendizagem revestido de teoria associada com a prática.

De acordo com o resultado do experimento, pode-se afirmar que: o açaí apresenta potencialidade para ser utilizado como indicador ácido-base, pois, desempenha muito bem tal função através da mudança de cor nas substâncias. Por ser um procedimento simples e de baixo custo, o açaí é uma boa escolha para a utilização em escolas sem laboratórios. Com essa prática os alunos também puderam perceber a importância das aplicações dos ácidos e bases no cotidiano e sua importância. 


\title{
THE TEACHING OF ACIDS AND BASES FROM THE NATURAL INDICATOR PRODUCED WITH AÇAÍ (Euterpeoleracea Mart)
}

\begin{abstract}
The present work shows a differentiated activity carried out with 3rd year students of High School in the Teaching of Chemistry, from a public school in Rorainópolis - Roraima. During the supervised internship IV, it was observed the difficulty of the students in assimilating the theme portrayed in the classes, because only theoretical expositions did not arouse their interest. Therefore, this research presents the teaching of acids and bases using an alternative indicator from açaí, aiming to improve students' understanding, through a contextualized action. The açaí extract acts as an indicator of acid and alkaline substances, since its natural pigments are responsible for the changes in coloration according to the medium. The results showed that the fruit is a good option to use as an indicator, as it performs this function very satisfactorily, through color variation. It is a simple and low-cost methodology, being a good choice in schools without laboratories or suitable materials. The proposal helped students to understand the importance of the applications of the subject discussed in everyday life and how their knowledge is essential today. The dynamics provided the approach and discussion of Chemistry contents, as well as its analogy with aspects of students' daily life.
\end{abstract}

Keywords: Chemistry Teaching. Alternative Materials. PIBID.

\section{REFERÊNCIAS}

CARMO, H.; FERREIRA, M. Metodologia da Investigação-Guia para Auto-aprendizagem 2. ed. Lisboa: Universidade Aberta, 2008.

CONSTANTINO, M. G.; DA SILVA, Gil Valdo José; DONATE, Paulo Marcos. Fundamentos de Química Experimental. Vol. 53. São Paulo: Edusp, 2004.

COSTA, Z. G.etal. Estudo da estabilidade de antocianinas extraídas dos frutos de açaí (Euterpeaoleracea Mart.). Blucher Chemical Engineering Proceedings, v. 1, n. 3, p. 2177 2182, 2015.Disponívelem: <http://pdf.blucher.com.br.s3-sa-east1.amazonaws.com/chemicalengineeringproceedings/cobeqic2015/365-33974-260982.pdf>. Acesso em 06 mar. 2017.

\section{DAMASCENO, D.et al. APLICAÇÃO DE EXTRATO DE AÇAÍ NO ENSINO DE}

QUÍMICA. Unidade de Ciências Exatas e Tecnológicas, UEG. v. 30, p. 06-11, 2005.

Disponível em: <http://www.prp2.ueg.br/06v1/conteudo/pesquisa/inic-

cien/eventos/sic2005/arquivos/exatas/aplicacao_extrato.pdf $>$.

DIAS, M. V.; GUIMARÃES, P. C; MERÇON F. Corantes naturais: extração e emprego como indicador de pH. Química nova na escola, n. 17, p. 27-31, 2003.

FLICK, Uwe. Introdução à pesquisa qualitativa. 3. ed. J. E. Costa, Trad.Artmed. São Paulo, 2009. /a07.pdf 
GERHARDT, T.; SILVEIRA, D. T. Métodosdepesquisa. Coordenado pela Universidade Aberta do Brasil - UAB/UFRGS e pelo curso de Graduação Tecnológica - Planejamento e Gestão para o DesenvolvimentoRural da SEAD/UFRGS. - Porto Alegre: Editora da UFRGS, 2009.

GIL, A. C. Como elaborar projetos de pesquisa/Antônio Carlos Gil. 4.ed. São Paulo: Atlas, 2008.

LUCAS, M.et al. Indicador natural como material instrucional para o ensino de química. Experiências em Ensino de Ciências, v. 8, n. 1, 2013. Disponível em:

<http://if.ufmt.br/eenci/artigos/Artigo_ID198/v8_n1_a2013.pdf>. Acesso em 16 fev. 2016.

MENEZES-COSTA. F. et al. Utilização do açaí como indicador natural ácido-base. $14^{\circ}$ Encontro de Profissionais da Química da Amazônia (14 EPQA). A Atuação dos Profissionais da Química frente aos Desafios Atuais. Pará, 2015. Disponível em:

$<$ http://www.14epqa.com.br/areas-tematicas/ensino-quimica/65-P430-434-utilizacao-do-acaicomo-indicador-natural-acido-base.pdf>. Acesso em 06 Dez. 2016.

PENAFORTE, G. S.; SANTOS V. S. dos. O ensino de química por meio de atividades experimentais: aplicação de um novo indicador natural de $\mathrm{pH}$ como alternativa no processo de construção do conhecimento no ensino de ácidos e bases. Revista EDUCAmazônia Educação Sociedade e Meio Ambiente, v. 8, n. 2, p. 8-21, 2014. Disponível em: <dialnet.unirioja.es/descarga/articulo/4731867.pdf>. Acesso em 05 dez. 2016.

PRODANOV, C. C.; FREITAS, E. C. Metodologia do Trabalho Científico: Métodos e Técnicas da Pesquisa e do Trabalho Acadêmico. 2. ed. Novo Hamburgo - RS: Feevale, 2013.

RAMPAZZO, L. Metodologiacientífica. 3. ed . São Paulo: Edições Loyola, 2005.

SANTOS, L. G. V. dos.etal. Indicadores naturais ácido-base a partir de extração alcoólica dos pigmentos das flores Hibiscus rosa-sinensis e Iroxachinensi, utilizando materiais alternativos. In: VII CONNEPI-Congresso Norte Nordeste de Pesquisa e Inovação. 2012. Disponível em:

<http://propi.ifto.edu.br/ocs/index.php/connepi/vii/paper/viewFile/1352/1154>. Acesso em 14 mar. 2017.

SILVA, L.O, et al. Clube de ciências e as tendências educacionais aplicadas no contexto regional Amazônico.Scientia Plena. v. 12, n. 6, Belém, 2016. Disponível em: <https://www.scientiaplena.org.br/sp/article/view/3040/1499>. Acesso em: 14 fev. 2017.

SOUZA, J. R. da. T. Instrumentação para o ensino de química. ed. UFPA, Belém, 2011. Disponível em: <http://www.aedi.ufpa.br/editora/index.php/download/send/0-/19instrumentacao-para-o-ensino-de-quimica>. Acesso em 04 mar. 2017. 
SOUZA, J. R. da. T. , M. O. et al. Açaí (EuterpeoleraceaeMartius): composição química e bioatividades.Nutrire: rev. Soc. Bras. Alim. Nutr.=J. Brazilian Soc. Food Nutr, São Paulo, SP, v. 36, n. 2, p. 161-169, ago. 2011. Disponível em: <

http://sban.cloudpainel.com.br/files/revistas_publicacoes/334.pdf>. Acesso em 13 fev. 2017.

TERCI, D. B. L.; ROSSI, A. V. Indicadores naturais de pH: usar papel ou solução?. Química Nova, v. 25, n. 4, p. 684-688, 2002. 